\title{
GESTÃO INSTITUCIONAL DE CRISES ESTRUTURAIS: A (IN)EFETIVIDADE DO SISTEMA DE JUSTIÇA BRASILEIRO FRENTE A VIOLÊNCIA DE GÊNERO, DOMÉSTICA E/OU FAMILIAR
}

\author{
Artenira da Silva e Silva ${ }^{1}$ \\ Ítalo Viegas da Silva ${ }^{2}$
}

\section{RESUMO}

Este artigo debruça-se sobre o sistema de justiça brasileiro e o tratamento das demandas envolvendo violência doméstica e/ou familiar a partir da análise institucional e estrutural do fenômeno. Trata-se de um estudo sobre o compromisso que o sistema de justiça possui com o enfrentamento de uma crise tida como estrutural. Assim, o trabalho se dedicará ao levantamento de marcos históricos e dados secundários sobre o tema, a fim de observar se houve um avanço no enfrentamento do quadro ou somente a dita gestão institucional de crises estruturais.

Palavras-chave: sistema de justiça; violência doméstica e/ou familiar; crise estrutural; gestão institucional.

\section{INSTITUTIONAL MANAGEMENT OF STRUCTURAL CRISES: THE (UN)EFFICIENCY OF THE BRAZILIAN JUSTICE SYSTEM TOWARDS GENDER, DOMESTIC AND/OR FAMILY VIOLENCE}

\begin{abstract}
This article approaches Brazilian justice system and the treatment of the demands involving domestic and/or family violence from the institutional and structural analysis of the phenomenon. It's a study about the commitment that the justice system has with facing a crisis understood as structural. Therefore, the work will concentrate on the survey of historical landmarks and secondary data on the theme, in order to observe if there was an advance in facing the problem or simply the referred institutional management of structural crises.
\end{abstract}

Keywords: justice system, domestic and/or family violence, structural crisis, institutional management.

\section{INTRODUÇÃO}

\footnotetext{
${ }^{1}$ Pós-doutora em Direitos Humanos na Universidade Federal do Pará (2020), Pós-doutora em Psicologia e Educação pela Universidade do Porto- Portugal (2014), Graduada pela Psicologia pela Pontifícia Universidade Católica de São Paulo, Mestre em Saúde e Ambiente pela Universidade Federal do Maranhão (2000), Doutora em Saúde Coletiva pela Universidade Federal da Bahia (2005) e Docente da Universidade Federal do Maranhão no Programa de Pós-graduação de Direito e Instituições do Sistema de Justiça da UFMA, contato: artenirassilva@hotmail.com

${ }^{2}$ Mestrando no Programa de Pós-Graduação em Direito e Instituições do Sistema de Justiça (UFMA), Pósgraduando em Direito Civil e Consumidor (Uniamérica), Bacharel em Direito (UFMA) e Assessor de Juízo (TJMA), contato: italo.viegas@discente.ufma.br.
} 
O presente artigo tem como tema a compreensão da (in)efetividade do sistema de justiça no enfrentamento à violência de gênero, a partir das formas de concepção institucional e estrutural da sociedade brasileira.

Neste sentido, são dois os problemas de pesquisa que moveram a escrita deste texto. O primeiro repousa na necessidade de perspectiva para enfrentamento de crises estruturais, ou seja, aquelas relacionadas à desigualdade de renda, ao racismo e ao patriarcado, esta última objeto de pesquisa deste trabalho. Já o segundo, questiona se as ações adotadas pelas instituições do sistema de justiça de fato possuem a intenção de romper com a forma jurídica que reproduz e renova traços estruturais do Brasil ou se prestam somente ao que será nominado como "gestão institucional de crises estruturais".

A hipótese inicial aponta para a segunda possibilidade, ou seja, o sistema de justiça brasileiro transita entre episódios pontuais de proteção às mulheres vulnerabilizadas e a continuidade de uma cultura jurídica de manutenção das mesmas estruturas sociais estigmatizantes, a partir de pequenas concessões que configuram a dita gestão institucional das crises estruturais.

Isto posto, elegeu-se como objetivo geral analisar o sistema de justiça sob a ótica das concepções institucional e estrutural (ALMEIDA, 2019), a fim de alcançar objetivos específicos que fundamentem a hipótese supracitada, quais sejam: a) identificar importantes momentos históricos que podem ser configurados como vitórias das lutas sociais feministas; b) relacioná-los com dados secundários, extraídos principalmente do sítio eletrônico do Conselho Nacional de Justiça (CNJ); c) verificar se houve um avanço no enfrentamento da crise estrutural ou somente uma gestão institucional destas pelo sistema de justiça brasileiro.

A motivação da escrita está relacionada a inquietação pessoal e profissional diante da naturalização dos antagonismos que demarcam a forma de sociabilização brasileira (MASCARO, 2013). Logo, compreendemos como fundamental lançar lentes não habituais para enxergarmos a realidade, a fim de que os novos compromissos e ações, não só do sistema de justiça, estejam alinhados com a superação de um modelo de sociedade que torna, por vezes, a vida mais dolorosa que a morte literal para a população feminina e seus familiares.

Para tanto, inicialmente será apresentada a metodologia adotada, enquanto os capítulos seguintes versarão sobre o que no presente estudo está conceituado como crises 
estruturais e a razão pela qual são assim identificadas, bem como sua relação com as instituições, em especial as do sistema de justiça. O texto se dedicará ao levantamento de marcos históricos que tangenciam a proteção as mulheres em face da violência de gênero e dados secundários sobre o tema, extraídos de fontes secundárias do $\mathrm{CNJ}$, a fim de diagnosticar a (in)efetividade destas ações. Por fim, fundamentar-se-á a pertinência conceitual do termo "gestão institucional de crises estruturais" no âmbito do sistema de justiça.

\section{METODOLOGIA}

Para a elaboração do presente artigo, entrou-se em contato com noções elementares da pesquisa científica, para só então definir os métodos de abordagem, procedimento e técnicas de pesquisa adequadas.

Considerando durante toda a feitura do artigo que a pesquisa acadêmica, compreendida como "[...] investigação: busca realizada de forma sistemática" (MEZZAROBA; MONTEIRO, 2009, p. 105), tem por objetivo fornecer respostas ainda não encontradas para temas inovadores ou mesmo já amplamente estudados.

Dito isto, a natureza da pesquisa empreendida neste artigo é quanti-qualitativa, na medida que se propõe a interpretar fenômenos a partir da coleta de dados estatísticos secundários e os pressupostos conceituais estabelecidos.

Além disso, se adotou a modalidade descritiva da pesquisa (MEZZAROBA; MONTEIRO, 2009), posto que o artigo majoritariamente tem a intenção de diagnosticar a realidade, sem prescrever soluções acabadas, mas tangenciá-las. Feitas tais considerações, adota-se o método de abordagem dedutivo, pois a pesquisa parte do conhecido para o desconhecido, bem como tem seu alcance limitado ao fenômeno e hipótese apresentados (MEZZAROBA; MONTEIRO, 2009).

\section{CRISES ESTRUTURAIS}

Quais são as ideias que levaram à categorização do patriarcado e seus desdobramentos como uma crise estrutural? 
A noção de crise estrutural tem sua ideia fundamentada na percepção de que todos estes males não são episódicos, ou seja, não devem ser lidos como um acidente no percurso da história, um momento nebuloso que logo passará. Pelo contrário, a desigualdade de gênero constitui a dita normalidade ${ }^{3}$ da sociedade brasileira, mais que o trivial, é um dos fundamentos da forma de socialização, compõem alguma das estruturas mais bem sedimentadas sobre as quais se organizam os indivíduos e as instituições da sociedade (MASCARO, 2013).

Dando continuidade à conceituação de crises estruturais, estas apresentam-se como verdadeiro oximoro, pois a crise carrega consigo a ideia de excepcionalidade, mas dentro do contexto estudado, constitui a regularidade (SANTOS, 2020). Logo, o termo 'crise' não passa de uma provocação, pois apesar da realidade exposta ser digna desta nominação, suas condições de existência encontram-se “[...] sempre no seio de estruturas sociais já previamente consolidadas" (MASCARO, 2013, p. 200).

Empresta-se da contribuição singular de ALMEIDA (2019, p. 33) quando trata do racismo na sua acepção estrutural e diz:

Em resumo: o racismo é uma decorrência da própria estrutura social, ou seja, do modo "normal" com que se constituem as relações políticas, econômicas, jurídicas e até familiares, não sendo uma patologia social e nem um desarranjo institucional.

Bem, mas não finda ainda a noção de crise estrutural, ao menos dentro das limitações deste artigo científico, esta possui um outro viés, o ideológico. Isto porque, para além dos efeitos materiais claros outro elemento essencial das crises estruturais é a formação de um sistema de ideias que produz uma visão distorcida da realidade (ALMEIDA, 2019).

Quer-se dizer: de que modo a ideologia pode permitir que se naturalize tantas desigualdades? Como internalizar o distanciamento abissal entre experiências de existência a depender de gênero, orientação sexual ou renda?

3 Normalidade significa que as expressões de violência ao feminino são elementos centrais da nossa forma de organização e sociabilização, de tal modo que a sociedade não veja com espanto o fato das mulheres receberem, por exemplo, os menores salários. É em razão da normalidade que não há estranhamento aos diversos mecanismos de opressão do gênero feminino. 
Quando ALMEIDA (2019, p. 40) relaciona racismo e ideologia propõe que para obter-se a resposta "[...] o racismo, enquanto processo político e histórico, é também um processo de constituição de subjetividades, de indivíduos cuja consciência e afetos estão de algum modo conectados com as práticas sociais".

$\mathrm{O}$ autor continua e pontua que o racismo se perpetua a partir da produção de um conjunto de ideias capazes de explicar racionalmente a existência da desigualdade racial e da constituição de sujeitos incapazes de se abalar diante da violência racial, considerando trivial e natural a existência de "brancos" e "não brancos".

Acrescentamos, as estruturas sociais renovam crises a partir da atuação de suas instituições e sujeitos indiferentes até mesmo às suas próprias encruzilhadas, soterrados por antagonismos extremos, que passam a ser racionalizados a partir de uma percepção que naturaliza absurdos, ao invés de contestá-los, frequentemente sem sequer causar qualquer estranhamento.

Buscando tangenciar outros temas, a fim de melhor compreender a ideia de crise estrutural, insere-se brevemente o debate sobre a desigualdade de renda. Tema extremamente complexo, pois tangencia outros elementos conceituais além do monetário, como a autoestima social de trabalhadores que vem perdendo sua relevância social em relação a seus pares, deixada para trás nas promessas da globalização econômica (SANDEL, 2021). Propõe-se a reflexão sobre como é cognoscível que num país em que dezenove milhões de pessoas passaram a compor o mapa da fome em 2020, em comparação ao ano de 2018, quando o número era de aproximadamente dez milhões ${ }^{4}$, ao mesmo tempo é capaz de fertilizar o que restou demonstrado pelo ranking dos Bilionários de 2021, onde o número de bilionários brasileiros aumentou em 44\% entre 2020 e 2021, revelando um acúmulo na riqueza deste grupo no montante de 127,1 para 219,1 bilhões de dólares ${ }^{5}$

4 Sobre o tema, ler o relatório Insegurança Alimentar e Covid-19 no Brasil. Rede Brasileira de Pesquisa em Soberania e Segurança Alimentar e Nutricional. 2021. Disponível em: http://olheparaafome.com.br/VIGISAN_Inseguranca_alimentar.pdf. Acesso em 29 jul. 20121.

5 Para mais informações, ver o relatório A quantas anda a desigualdade de rendimentos no Brasil? Observatório das Desigualdades. 2020. Disponível em: http://observatoriodesigualdades.fjp.mg.gov.br/?p=1413. Acesso em 29 jul. 20121. 
No mesmo sentido, pensar a desigualdade de gênero revela contradições alarmantes, pois no mesmo país em que 28,9 milhões de mulheres são chefes de família ${ }^{6}$, estas continuam recebendo "[...] 77,7\% do salário dos homens, ao ocuparem as mesmas funções que eles, em 2019. A diferença é ainda mais elevada em cargos de maior rendimento, como diretores e gerentes. Nesse grupo, as mulheres ganharam apenas $61,9 \%$ do rendimento dos homens."7. Não só, ainda são assoladas pela violência de gênero, reconhecida como uma Pandemia invisível segundo a ONU Mulheres ${ }^{8}$, onde no Brasil oito mulheres são agredidas por minuto, mas somente $24,7 \%$ buscam algum órgão oficial do sistema de justiça ${ }^{9}$ em busca de proteção estatal.

Além disso, as crises estruturais não existem de modo isolado, ou seja, sobre uma mulher não recai somente o peso da desigualdade de gênero, mas também o do racismo, da homotransfobia ou qualquer outra forma de existência diversa da heteronormativa. Logo, são várias as intersecções possíveis que conjuntamente formam encruzilhadas de resistência e violência (AKOTIRENE, 2019).

Neste sentindo, segundo o IPEA (2016) ${ }^{10}$, entre 1995 e 2015:

[...] a escala de remuneração manteve-se inalterada em toda a série histórica: homens brancos têm os melhores rendimentos, seguidos de mulheres brancas, homens negros e mulheres negras. A diferença da taxa de desocupação entre sexos também merece registro: em 2015, a feminina era de $11,6 \%$, enquanto a dos homens atingiu $7,8 \%$. No caso das mulheres negras, ela chegou a $13,3 \%$ (e $8,5 \%$ para homens negros)

6 Ver pesquisa CAVENAGUI, Suzana; ALVES, José Eustáquio Diniz Alves. MULHERES CHEFES DE FAMílIA NO BRASIL: AVANÇOS E DESAFIOS. Rio de Janeiro: ENS-CPES, 2018. Disponível em: https://www.ens.edu.br/arquivos/mulheres-chefes-de-familia-no-brasil-estudo-sobre-seguro-edicao-32_1.pdf. Acesso em 29 jul. 20121.

7 Para mais informações, ver GUEDES, Mylena. Mulheres ganham 77,7\% do salário dos homens no Brasil, diz IBGE. CNN, 2021. Disponível em: https://www.cnnbrasil.com.br/business/2021/03/04/mulheres-ganham77-7-dos-salarios-dos-homens-no-brasil-diz-ibge. Acesso em 29 jul. 20121.

8 Ver pesquisa Violência contra as mulheres e meninas é pandemia invisível, afirma diretora executiva da ONU Mulheres. ONU, 2020. Disponível em: https://www.onumulheres.org.br/noticias/violencia-contra-asmulheres-e-meninas-e-pandemia-invisivel-afirma-diretora-executiva-da-onu-mulheres/. Acesso 29 jul. 20121.

9 Sobre o tema, ver o relatório Visível e Invisível: A Vitimização das Mulheres no Brasil. $3^{\text {a }}$ edição - 2021. Disponível em: https://forumseguranca.org.br/wp-content/uploads/2021/06/relatorio-visivel-e-invisivel-3ed2021-v3.pdf. Acesso 29 jul. 20121.

10 Ver pesquisa Estudo mostra desigualdades de gênero e raça em 20 anos. IPEA, 2016. Disponível em: https://www.ipea.gov.br/portal/index.php?option=com_content\&view=article\&id=29526. Acesso 29 jul. 20121. 
As estruturas que edificam estas realidades, que moldam subjetividades incapazes de se chocarem ou de se subverterem em face de tais desigualdades é uma das facetas mais perversas das crises, pois seus fundamentos são ideias falseadas da realidade, configurando como muito mais difícil enfrentar ou destruir o que sequer se reconhece de fato que existe.

Portanto, assim caracterizam-se as crises estruturais: a) males inegavelmente nocivos à sociedade como um todo, mas que maltratam substancialmente grupos estigmatizados e que, portanto, são rotineira e indefinidamente vulnerabilizados; b) não estão presentes em momentos pontuais da história do Brasil, são, ao contrário, o fundamento da sociedade brasileira e confundem-se, porque o são, com a normalidade; c) renovam-se a partir da subjetividade e prática das instituições, com fundamento no elemento ideológico, com aptidão suficiente para racionalizar a desigualdade gerada pelo gênero; d) atravessam as instituições e os indivíduos concomitantemente, nunca de forma isolada, naturalizando a ideia de conflito permanente da sociedade capitalista.

\section{A RELAÇÃO ENTRE AS CRISES ESTRUTURAIS E AS INSTITUIÇÕES}

Como uma sociedade, sabidamente contraditória, segue reproduzindo mazelas já identificadas e com regulação positivada pelo ordenamento jurídico, inclusive na forma de direitos fundamentais ou tratados de direitos humanos internalizados?

Uma das formas de elucidar esta questão é o pensamento trazido por HIRSCH (2007, p. 48):

Gidenns assim formula o problema: 'Sem ação humana não haveria de modo algum sociedades humanas, ou sistemas sociais. Mas isso não quer dizer que os atores criaram sistemas sociais: eles o reproduzem e os modificam, no que sempre os renovam'.

Outra contribuição importante é a de MASCARO (2013, p. 199):

Como elemento fundamental da reprodução da dinâmica capitalista, o Estado é menos um meio de salvação social do que, propriamente, um dos elos da própria crise. Por ele passa a crise remediada, majorada ou reelaborada. A forma política altera circunstâncias econômicas e sociais que, 
se ensejam novas articulações, quase sempre são parciais, mantendo as bases gerais da valorização do valor. O mesmo se dá com a forma jurídica. Por mais variáveis que sejam os remédios jurídicos tomados em situações de crise do capital - de eventuais expropriações a aumento ou extinção de direitos sociais -, a alteração dos institutos jurídicos não chega à ruptura da forma jurídica. O sujeito de direito continua sendo base para a reprodução social, garantindo assim o circuito mercantil e o capital.

É sob esta égide que as instituições desempenham papel fundamental para o presente artigo, pois nestas ocorrem tanto uma ação dirigida e intencional de grupos hegemônicos, como também a reprodução e renovação de práticas sociais a partir de condições preestabelecidas pelo modo de sociabilização vigente (HIRSCH, 2007).

Neste sentido:

A estabilidade dos sistemas sociais depende da capacidade das instituições de absorver os conflitos e os antagonismos que são inerentes à vida social. Entenda-se absorver como normalizar, no sentido de estabelecer normas e padrões que orientarão a ação dos indivíduos. (ALMEIDA, 2019, p. 26)

Observar este aspecto revela que as instituições carregam em si o "conjunto de significados previamente estabelecidos pela estrutura social” (ALMEIDA, 2019 p. 26), pois os mesmos conflitos que afligem a sociedade também lhes alcança e as constitui.

Assim, a normalização e padronização de comportamentos fomentadas pelas instituições absorvem as contradições e lutas sociais, mantendo estas erupções externas e internas no âmbito do seu controle (ALMEIDA, 2019). Portanto, a precarização da vida, em suas mais diversas possibilidades, não decorre da ação isolada de um grupo ou pessoa, mas sim porque as instituições possuem a capacidade de impor os valores e interesses hegemônicos dos grupos dominantes (HIRSCH, 2007).

Desta forma, Poder Judiciário, Executivo, Legislativo, TV, Rádio, Redes Sociais, Empresas privadas, Família e outras instituições passam a externar manifestações “compatíveis com a reprodução do conjunto das relações sociais" (HIRSCH, 2007, p. 53). Cria-se, incontestavelmente, a noção de "normal" dentro da sociedade, o que é demasiadamente perigoso, pois o "normal" pode ser, como é, a perpetuação de um modo de viver necessariamente marcado pelo conflito de discrepâncias entre modos de existir a 
depender da renda, trabalho, gênero, orientação sexual ou cor de pele, na absoluta contra mão do que se poderia identificar como modos de existir saudáveis e compatíveis com a vida em uma sociedade garantidora de direitos fundamentais, na qual todos seriam "iguais" perante a lei..

Este é o grande mérito das instituições, pois:

[...] a manutenção desse poder adquirido depende da capacidade do grupo dominante de institucionalizar seus interesses, impondo a toda sociedade regras, padrões de condutas e modos de racionalidade que tornem "normal" e "natural" o seu domínio. (ALMEIDA, 2019, p. 27).

Isto posto, como as instituições do sistema de justiça relacionam-se com as estruturais sociais, especialmente a patriarcal?

\subsection{COMO ATUAM AS INSTITUIÇÕES DO SISTEMA DE JUSTIÇA BRASILEIRO?}

É possível tomar como exemplo o perfil sociodemográfico dos magistrados brasileiros, majoritariamente pessoas do sexo masculino, brancos e oriundas de famílias com alta escolaridade ${ }^{11}$.

Contudo, tal verificação é insuficiente para identificar a relação das instituições do sistema de justiça com a crise estrutural patriarcal. Isto porque o sistema de justiça vai muito além do Poder Judiciário em si, pois também é composto por delegacias, casas de acolhimento, presídios, defensorias públicas, ministério público etc.

Apesar da diversidade, é possível caracterizar as instituições do sistema de justiça nacional como integrantes de um conjunto encarregado de garantir a efetividade e alcance dos preceitos constitucionais (SADEK, 2002), infralegais e internacionais, tendo como marco interpretativo a dignidade da pessoa humana.

11 Ver o relatório Perfil Sociodemográfico dos Magistrados Brasileiros 2018. CNJ, 2018. Disponível em: https://www.cnj.jus.br/wpcontent/uploads/2019/09/a18da313c6fdcb6f364789672b64fcef_c948e694435a52768cbc00bda11979a3.pdf. Acesso 29 jul. 20121.

Revista de Gênero, Sexualidade e Direito | e-ISSN: 2525-9849 | Encontro Virtual | v. 7 | n. 2 |

p. $42-61$ | Jul/Dez. 2021. 
Os relatórios de metas do Conselho Nacional de Justiça (CNJ) entre 2009 e 2020 são um bom indicador do compromisso do sistema de justiça com enfrentamento à violência doméstica e/ou familiar. Assim, entre os anos de 2009 e $2016^{12}$, a demanda relacionada à violência de gênero sequer constavam entre as metas do $\mathrm{CNJ}$, passando a compor expressamente as prioridades do sistema de justiça a partir de 2017 e tendo como objetivo o fortalecimento da rede de enfrentamento à violência doméstica e/ou familiar contra as mulheres.

Contudo, os dados do CNJ (2017) revelam aspectos contraditórios deste suposto compromisso com as mulheres em situação de violência, isto porque naquele ano somente $37,04 \%$ dos tribunais cumpriram a meta estabelecida. Quadro que se manteve no ano seguinte, quando então 48,15\% dos tribunais cumpriram a meta estipulada (CNJ, 2018).

A partir de 2019 houve uma alteração no conteúdo da meta, que passou a priorizar o julgamento dos processos relacionados ao feminicídio e à violência doméstica e familiar contra as mulheres, com a obrigação de identificar e julgar 50\% dos casos pendentes de julgamento. Desta forma, no caso dos crimes de feminicídio, somente 51,85\% dos tribunais obtiveram êxito em alcançar o objetivo, já nos crimes de violência doméstica o percentual foi de $55,56 \%$ (CNJ, 2019).

Por fim, em 2020, quando o objetivo da meta foi o mesmo do ano anterior, houve o cumprimento de $182,72 \%$ no caso dos crimes de feminicídio e 63,13\% consoante aos processos relacionados à violência doméstica e familiar contra a mulher (CNJ, 2020). Importante destacar que diferente dos anos anteriores, os dados divulgados deram-se em termos gerais e não de acordo com a produtividade de cada um dos tribunais de justiça isoladamente.

A sensação de avanço ao longo dos anos é falseada, ao menos quanto aos dados ora apresentados, pois enquanto entre 2017 e 2018 as metas abrangiam itens como o percentual de unidades judiciária que dispõem de equipe de atendimento multidisciplinar ou de unidades com atendimento destinado a familiares dependentes em situação de violência doméstica, com

12 Para mais informações, verificar Relatórios de Metas do CNJ entre os anos de 2009 e 2013. Disponível em: https://www.cnj.jus.br/gestao-e-planejamento/metas/relatorios-anteriores/. Acesso 29 jul. 20121. 
especial atenção a crianças e adolescentes ${ }^{13}$, a partir de 2019 o enfrentamento a esta crise passou a ser analisado apenas a partir do número de processos identificados e julgados.

É fundamental questionar qualquer estatística que se limite a mera análise quantitativa de dados multifacetados e complexos, pois parte da crise que envolve a desigualdade de gênero reside na ausência de compreensão do fenômeno e da dimensão dos danos perpetrados em face de uma mulher em situação de violência doméstica ou familiar.

Assim, partindo do pressuposto que nem mesmo este texto está livre dos conflitos demarcados pelas estruturas sociais do patriarcado, colonialismo e capitalismo, o sistema de justiça também não está, de tal modo que a regra deste é a reprodução, em suas atividades, das mesmas práticas sociais que renovam a crise estrutural patriarcal, o que encontra-se devidamente materializado em peças processuais, demandando estudos qualitativos sobre os referidos documentos.

Várias são as produções acadêmicas que identificam e preocupam-se em propor novos caminhos para as reverberações desta crise, a exemplo da propositura de ações interinstitucionais contra a violência de gênero praticada pelo agressor primário e secundário (SILVA; PEREIRA; BERTOLIN; MANSO, 2020), da análise da tortura institucional via poder Judiciário (OLIMPIO, 2021), das violências que são invisibilizadas pelo poder Judiciário (SANTOS, 2021) ou ainda da necessidade de se reconhecer o dano existencial ao projeto de vida da mulher em situação de violência (LEITE, 2021).

Entretanto, os alertas da academia não raramente passam desapercebidos ou mesmo são ignorados pelas instituições, que se recusam ou não se encontram academicamente qualificadas para adotarem uma postura de rompimento com a reprodução de um direito eminentemente masculino (SMART, 1992), pautado numa prática liberal-individualistanormativa (STRECK, 1999). Seguem com a prática característica da chamada "gestão institucional de crises estruturais", ou seja, realizando pequenas concessões durante o processo histórico e político, mas sempre mantendo as pautas e decisões fundamentais sob o domínio e em proteção aos interesses dos grupos hegemônicos e dominantes (ALMEIDA, 2019).

13 Dado retirados de Metas Nacionais do Poder Judiciário 2017. Glossário e Esclarecimentos. Justiça Estadual. $2017 . \quad$ CNJ, Disponível $\quad$ em: https://www.cnj.jus.br/wpcontent/uploads/2016/12/647ce9b3aeafe3f54d3832731c925406.pdf. Acesso 29 jul. 20121. 


\subsection{MARCOS JURÍDICOS E A (IN)EFETIVIDADE DO SISTEMA DE JUSTIÇA}

As soluções legislativas e jurídicas habituais possuem um problema marcante no que diz respeito à tratativa do conflito da vida real enquanto um mero litígio processual, promovendo "[...] a dessingularização de seu conteúdo e a juridificação de sua forma" (AQUINO, 2020). Há um deslocamento ideológico-discursivo que consiste na prática do sistema de justiça em se deparar com problemas e tensões sociais complexas e tornar todo o debate em torno do fenômeno em algo abstrato, definido em termos jurídicos, interpretáveis e passivos de decisão. Existe uma passagem do "discurso DE" para o "discurso SOBRE" (STRECK, 1999).

O sistema de justiça, acomodado em métodos jurídicos tradicionais, ignora a necessidade de enfrentar a violência de gênero a partir de métodos feministas, ou seja, de formas de apreender a realidade a partir da experiência feminina (BARTLETT, 1990).

Quando se propõe a reflexão sobre marcos jurídicos, certamente se faz menção a Lei $\mathrm{n}^{\circ} 11.340 / 2006$ e suas alterações posteriores, conhecida como Lei Maria da Penha, que tem por objetivo coibir a violência doméstica e familiar contra a mulher, reconhecida como " $[$...] a expressão máxima da desigualdade nas relações de gênero [...]” (SAUAIA; PASSOS, 2016, p. 140).

Cita-se também o Decreto no 1.973/96, que internalizou a Convenção Interamericana para Prevenir, Punir e Erradicar a Violência Contra a Mulher, chamada também de Convenção de Belém do Pará. Ainda, a Lei no 13.104/2015 que insere o feminicídio como qualificadora do crime de homicídio e inclui o feminicídio no rol de crimes hediondos.

Do ponto de vista da produção jurisprudencial, o Supremo Tribunal Federal julgou a ADC 19/DF e da ADI 4.424/DF, ao passo que o Superior Tribunal de Justiça produziu as das súmulas no $536,542,588,589$ e 600.

Não se quer aqui exaurir o processo histórico em questão, mas sim pontuar que todos estes marcos jurídicos são ao mesmo tempo fruto da luta dos movimentos sociais feministas (DEBERT, PERRONE, 2018), mas também constituem um traço marcante das instituições, 
qual seja, o de oferecer respostas episódicas a uma demanda estrutural, nunca rompendo com os alicerces do patriarcalismo.

É dentro deste cenário que se discute a (in)efetividade do sistema de justiça brasileiro frente à violação de direitos humanos de mulheres em âmbito doméstico e ou familiar. De um lado o sistema de justiça brasileiro pode afirmar que se preocupa com a desigualdade de gênero e a sua reverberação mais cruel, apresentando, para tanto, sua longa produção legislativa, jurisprudencial e administrativa.

Contudo, doutra perspectiva "Os estudos e etnografias sobre as delegacias, sobre os JECRIMs e sobre os JVDs em suas críticas ao desempenho dessas instituições têm reiterado o fato de "a vítima não ser ouvida pelos agentes institucionais" (DEBERT, PERRONE, 2018, p. 425), o que revela a inobservância de algo proposto a pelo menos trinta anos por BARTLETT (1990), quando apresenta métodos jurídicos feministas voltados à prática de se fazer a pergunta para as mulheres ou de se dá atenção aos contornos da realidade antes da abstração da lei.

Noutro sentido, chama-se atenção aos dados do Estado do Maranhão, que de acordo com levantamento entre os anos de 2014 e 2018, mais da metade das ações penais ajuizadas prescreveram, revelando a inefetividade institucional do Judiciário local (MAIA, 2020). É uma situação dramática, pois se nem mesmo as respostas institucionais mínimas se mostram eficazes, como se pode pensar na superação de uma crise estrutural?

Por fim, durante a Pandemia da COVID-19 foi possível verificar como as inúmeras ações institucionais ao longo dos anos, desvinculadas do compromisso de romper com a crise estrutural da desigualdade de gênero, estão aptas a alterar o atual paradigma da violência doméstica:

Chamam a atenção dois fatores que não se modificaram nas três edições da pesquisa $(2017,2019$ e 2021): as mulheres sofreram mais violência dentro da própria casa e os autores de violência são pessoas conhecidas da vítima, o que concede um alto grau de complexidade ao enfrentamento da violência de gênero no que se refere à proteção da vítima, punição do agressor e medidas de prevenção. Os dados aqui apresentados nos revelam que a crise sanitária só torna o seu enfrentamento ainda mais difícil: mulheres convivendo mais tempo com seus agressores, perda de renda familiar, aumento das tensões em casa, maior isolamento da mulher e consequente distanciamento de uma 
potencial rede de proteção (ONU MULHERES, 2020; RAUHAUS et al, $2020)^{14}$.

Destacamos que não se pretende diminuir a importância de qualquer medida institucional que se dedicou ao enfrentamento da violência de gênero, ao contrário, reitera-se a essencialidade destas e dos movimentos sociais que seguem galgando conquistas, independente da sua dimensão.

Contudo, é fundamental questionar se houve ao longo dos anos um deslocamento do centro de poder, ou seja, se a passagem do poder decisório foi conferido às mulheres ou se estas apenas tiveram suas demandas atendidas por um grupo hegemônico que segue inabalado e fazendo concessões pontuais para administrar os antagonismos do patriarcado.

\section{SOBRE A DITA GESTÃO INSTITUCIONAL DE CRISES ESTRUTURAIS}

A inefetividade do sistema de justiça frente à violência de gênero é sabidamente diagnóstica por diversas pesquisas, trata-se então de uma situação conhecida, que segue sendo encarada enquanto uma demanda privada, ao passo que deveria ser analisada sob a ótica da violação de direitos humanos.

Com acertada razão, entre as causas que dificultam o tratamento adequado a mulher em situação de violência estão:

[...] falta de investimento público para a criação das estruturas necessárias e a formação de recursos humanos suficientes e adequadamente capacitados para o atendimento da violência baseada no gênero. A qualificação dos profissionais é condição para o bom atendimento que irão oferecer e também um dos critérios para definir a especialização dos serviços. Não se trata apenas de ter bom domínio sobre os procedimentos administrativos, ou das técnicas de atendimento ao público, mas conhecer e compreender as especificidades da violência baseada em gênero [...] A falta de especialização dos profissionais é um obstáculo ao acesso das mulheres à justiça e pode ocorrer e se repetir em diferentes momentos do atendimento desde o primeiro balcão, onde a mulher solicita informações, até decisão judicial (PASINATO, 2018, p. 424)

14 Idem Nota de Rodapé no 6 
Outro aspecto identificado na pesquisa que envolveu o estudo empírico em 05 capitais brasileiros a partir da entrevista de 64 operadores do direito foi a confirmação que:

[...] atendimentos e encaminhamentos ocorrem de acordo com o "perfil" do profissional (da delegada titular, do juiz etc., e de cada um dos membros de suas equipes), fazendo com que o acesso das mulheres aos seus direitos seja condicionado por uma maior ou menor sensibilidade do profissional e conhecimento sobre a gravidade do problema da violência baseada em gênero. (PASINATO, 2018, p. 424)

Assim, mesmo em um primeiro momento é possível inferir que há um conflito entre a legislação protetiva da mulher em situação de violência e a capacitação dos profissionais que atuam no sistema de justiça para significa-la e operá-la devidamente. Também é possível afirmar que existe a ausência de investimento nos espaços físicos e nos recursos humanos de todas as instituições que compõe a Rede de proteção a mulheres, razão pela qual o acesso à justiça pode torna-se tão ou mais cruel quanto a violência primária. Compreende-se que todas estas hipóteses são verdadeiras e compõem parte central do debate em torno da violência doméstica e/ou familiar.

Todavia, o conceito de Gestão Institucional de Crises Estruturais busca lançar mão de outro olhar, que apesar de mais sútil é igualmente preocupante e necessariamente complementar aos demais. A percepção enfatiza que as várias dificuldades apresentadas no sistema de justiça não são somente obstáculos a serem superados, mas também obstáculos produzidos pelas instituições para que sejam apenas e deliberadamente parcialmente vencidos, de forma gradativa, lenta e sem tocar os núcleos constituintes das instituições brasileiras, fundadas nas estruturas do capitalismo, colonialismo, racismo e patriarcado.

Gerir institucionalmente uma crise é ter a capacidade de utilizar a própria crise como anteparo frente à ruptura, ou seja, é reconhecer que as lutas sociais contra as marcas do patriarcado são uma realidade que batem às portas das instituições, interna e externamente, e sabidamente propor pequenos acordos ou cessões que sob determinada perspectiva podem ser lidos como vitórias sociais, mas sob outra, constituem o manejo dos conflitos a partir de soluções litigiosas e avanços que não significam a reconfiguração das relações de poder (ALMEIDA, 2019), ao passo que conferem aos grupos hegemônicos que se renovam no seio 
das instituições, a legitimidade e reconhecimento social para seguir pautando as decisões centrais que não tem por objetivo romper com a crise estrutural.

Gerir crises estruturais institucionalmente é então adotar políticas que são incapazes de abalar nossa forma de sociabilização, reconhecida por este trabalho como deliberadamente contraditória e desumana, pois tem como forma predominante a violência material, moral e simbólica em face do feminino.

Neste sentido, este sentimento antagônico entre o aumento de dispositivos legais que conferem proteção jurídica às mulheres e a dificuldade de se vislumbrar, em um futuro próximo, a diminuição significativa de casos de violência doméstica e/ou familiar não reside unicamente na ausência de boas práticas institucionais limitadas a alguns parcos representantes institucionais individuais por aqueles que compõem o sistema de justiça, mas também na ausência de um compromisso institucional coletivo que vise transpor o atual paradigma patriarcal que rege as relações jurídicas e privilegia a condição integral de sujeito de direito àqueles que compõem um único grupo social, representado por uma minoria numérica, mas uma maioria política e econômica.

Ainda, compreender o fenômeno da violência de gênero a partir da gestão institucional de uma crise estrutural permite estar atento e crítico diante dos, em geral, limitados avanços sociais, sempre questionando aos cedentes: por qual razão só se caminhou até este ponto? o que impede que se avance ao ponto seguinte?; a quem interesse a continuidade da violência de gênero contra mulheres em âmbito doméstico e ou familiar?; quem é favorecido com a ausência de capacitação das instituições do sistema de justiça?

Analisar quanti qualitativamente a gestão institucional das crises estruturais é ter a possibilidade de converter a concessão episódica e excepcional de direitos em estado contínuo e compromissado de quebra de paradigmas, a fim de que não haja cessões pontuais, mas sim a administração contínua de formas de existir com dignidade. Para que então a referência ao termo "crise" esteja vinculado a um momento isolado e não caracterizando um estado continuado de violações de direitos humanos.

\section{CONCLUSÕES}


A perspectiva estrutural sobre o patriarcado e as relações que vão se compondo durante o processo histórico carrega consigo uma possibilidade de futuro diversa, pois identificar e nomear a gestão institucional de crises estruturais é também um método, uma lente a partir da qual é possível significar a realidade, e que nos convida a pensar o direito, as normas e instituições a partir das estruturas mestras do Brasil: capitalismo, colonialismo, racismo e patriarcado.

Neste sentido, é fundamental o olhar crítico diante dos gritos de conquista vindo diretamente das instituições, seja em forma de legislação, orientação jurisprudencial ou qualquer outra manifestação. Pois, sem questionar a relevância dos avanços ao longo da história, é preciso reconhecer que os mesmos grupos hegemônicos ainda pautam o caminhar dos antagonismos sociais que sustentam suas relações de poder.

Por fim, considera-se fundamental a lição de que "Ao nomear as opressões de raça, classe e gênero, entende-se a necessidade de não hierarquizar opressões [...]”, pois o que fundamenta a escrita deste trabalho é o ímpeto de construir “[...] novos marcos civilizatórios, para que pensemos um novo modelo de sociedade." (AKOTIRENE,2019).

\section{REFERÊNCIAS BIBLIOGRÁFICAS}

ALMEIDA, Silvio Luiz de. Racismo Estrutural. São Paulo: Sueli Carneiro; Pólen, 2019.

AQUINO, Luseni Maria Cordeiro. Do CONFLITO ao LITÍGIO: Em busca de justiça no Sistema Interamericano de Direitos Humanos. Tese (Doutorado em Sociologia) Programa de Pós-Graduação em Sociologia. Universidade de Brasília (UNB), Brasília, 2020.

AKOTIRENE, Carla. Interseccionalidade. São Paulo: Sueli Carneiro; Pólen, 2019.

BARTLETT, Katharine T. Feminist Legal Methods. Havard Law Review. Volume 103, Number 4, Fevereiro, 1990.

CNJ. Relatório Metas Nacionais do Poder Judiciário 2017. Disponível em: https://www.cnj.jus.br/wpcontent/uploads/2017/05/e2b3f547f615250a8a2b85011f1ae489.pdf. Acesso 29 jul. 20121. 
CNJ. Relatório Metas Nacionais do Poder Judiciário 2018. Disponível em: https://www.cnj.jus.br/wpcontent/uploads/2019/05/13926ffe304159519caed2b504923ff5.pdf. Acesso 29 jul. 20121.

CNJ. Relatório Metas Nacionais do Poder Judiciário 2019. Disponível em: https://www.cnj.jus.br/wpcontent/uploads/2020/04/Relatorio_de_Metas_Nacionais_do_Poder_Judiciario_2019_2020_0 4_30.pdf. Acesso 29 jul. 20121.

CNJ. Relatório Metas Nacionais do Poder Judiciário 2020. Disponível em: https://www.cnj.jus.br/wp-content/uploads/2021/06/Relat\%C3\%B3rio-de-Metas-Nacionais2020-v.f.pdf. Acesso 29 jul. 20121.

DEBERT, Guita Grin; PERRONE, Tatiana Santos. Questões de poder e as expectativas das vítimas: dilemas da judicialização da violência de gênero. Revista Brasileira de Ciências Criminais. vol. 150. ano 26. p. 423-447. São Paulo: Ed. RT, dezembro 2018. Disponível em: https://www.sumarios.org/artigo/quest\%C3\%B5es-de-poder-e-expectativas-dasv\%C3\%ADtimas-dilemas-da-judicializa\%C3\%A7\%C3\%A3o-da-viol\%C3\%AAncia-deg\%C3\%AAnero. Acesso 29 jul. 20121.

HIRSCH, Joachim. Forma política, instituições políticas e Estado - I. Crítica Marxista, n. 24, 2007. p. 26. Disponível em: https://www.ifch.unicamp.br/criticamarxista/arquivos_bibliot ca/artigo212artigo1.pdf.

HIRSCH, Joachim. Forma política, instituições políticas e Estado - II. Crítica Marxista, n. 24, 2007. p. 26. Disponível em: https://www.ifch.unicamp.br/criticamarxista/arquivos_bibliot ca/artigo212artigo1.pdf.

LEITE, José Augusto Sá Costa. RESPONSABILIZAÇÃO CIVIL DO AGRESSOR E O DANO EXISTENCIAL DECORRENTE DE VIOLẾNCIA DOMÉSTICA E

FAMILIAR: efetividade na aplicação da Lei Maria da Penha no Brasil. Volume IV. $1^{\text {a }}$ ed. São Paulo: Escola Superior de Advocacia OAB SP, 2021.

MAIA, Maicy Milhomem Moscoso. Prescrição e Efetividade: análise das Ações Penais de competência da Vara de Violência Doméstica e Familiar Contra a Mulher de São Luís (2014-2018). Dissertação (Mestrado em Direito) - Programa de Pós-Graduação em Direito e Instituições do Sistema de Justiça. Universidade Federal do Maranhão (UFMA), São Luís, 2020. 
MASCARO, Alysson Leandro. Estado e Forma Política. São Paulo: Boitempo, 2013.

MacKinnon, Catharine. TOWARD A FEMINIST THEORY OF THE STATE. Cambridge, MA: First Harvard University Press paperback edition, 1989.

MEZZAROBA, Orides; MONTEIRO Cláudia S. Manual de Metodologia da Pesquisa no

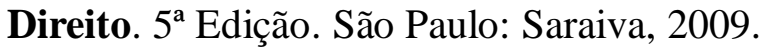

MOHANTY, Chandra Talpede. Feminist Sholarship and Colonial Discourses. Feminist Review, no 30. Autumn, 1988.

OLIMPIO, Werdeson Mário Cavalcante. TORTURA INSTITUCIONAL VIA PODER JUDICIÁRIO: quando a busca pela justiça é convertida em tortura às mulheres vítimas de violência doméstica e/ou familiar no Brasil. $1^{\text {a }}$ ed. São Paulo: Escola Superior de Advocacia OAB SP, 2021.

PASINATO, Wânia. ACESSO À JUSTIÇA E VIOLÊNCIA DOMÉSTICA E FAMILIAR CONTRA AS MULHERES: AS PERCEPÇÕES DOS OPERADORES JURÍDICOS E OS LIMITES PARA A APLICAÇÃO DA LEI MARIA DA PENHA. Revista Direito GV. São Paulo, p. 407-428, jul-dez, 2015.

SADEK, Maria Tereza Ainda. Estudos sobre o sistema de justiça. In S. Miceli, ed. O que ler na ciência social brasileira. V. 4. São Paulo: Sumaré, 2002.

SANDEL, Michael. A Tirania do Mérito: o que aconteceu com o bem comum? $4^{\mathrm{a}}$ Edição. Rio de Janeiro: Civilização Brasileira, 2021.

SANTOS, Boaventura de Sousa. A Cruel Pedagogia do Vírus. Coimbra: Almedina, 2019.

SANTOS, Érica Lene da Silva. VIOLÊNCIAS INVISIBILIZADAS: Uma análise sobre a efetividade do Poder Judiciário frente às ações decorrentes de violência moral e psicológica familiar e ou doméstica contra a mulher. Volume II. $1^{\mathrm{a}}$ ed. São Paulo: Escola Superior de Advocacia OAB SP, 2021. 
SAUAIA, Artenira da Silva e Silva; PASSOS, Kennya Regyna Mesquita. A violência simbólica no Poder Judiciário: desafios à efetividade da Lei Maria da Penha. Revista da Faculdade de Direito da UFRGS. Porto Alegre, n. 35, p. 137-154, dez. 2016.

SILVA, Artenira da Silva; PEREIRA, Flávio de Leão Bastos; BERTOLIN, Patrícia Tuma Martins; MANSO, Almudena Garcia. Mulheres Vivendo Sem Violência. Pelo fim da violência contra mulheres no Brasil: Novos caminhos apontados por análise de dados empíricos. Volume V. $1^{\mathrm{a}}$ ed. São Paulo: Escola Superior de Advocacia OAB SP, 2020.

SMART, Carol. La teoría feminista y el discurso jurídico. Social \& Legal Issues: An Internacional Journal, 37-53, 1992.

STRECK, Lênio Luiz. Hermenêutica Jurídica e(m) crise. Uma exploração hermenêutica da construção do direito. Porto Alegre: Livraria do Advogado, 1999. 